OPEN ACCESS

Edited by:

Spyridon Ntougias,

Democritus University of Thrace,

Greece

Reviewed by:

Tarique Hussain,

Nuclear Institute for Agriculture and Biology, Pakistan

BiE. Tan,

Chinese Academy of Sciences, China

*Correspondence:

Congmin Wang

wcm_8088@163.com

Xi Ma

maxi@cau.edu.cn

${ }^{t}$ These authors have contributed equally to this work

¥ORCID:

Han Liu

orcid.org/0000-0003-2126-4315

Xi Ma

orcid.org/0000-0003-4562-9331

Specialty section:

This article was submitted to

Systems Microbiology,

a section of the journal

Frontiers in Microbiology

Received: 10 August 2020 Accepted: 13 October 2020 Published: 25 November 2020

Citation:

Liu H, Wang C, Gu X, Zhao J, Nie C, Zhang $W$ and Ma $X$ (2020)

Dietary Montmorillonite Improves

the Intestinal Mucosal Barrier and Optimizes the Intestinal Microbial

Community of Weaned Piglets.

Front. Microbiol. 11:593056.

doi: 10.3389/fmicb.2020.593056

\section{Dietary Montmorillonite Improves the Intestinal Mucosal Barrier and Optimizes the Intestinal Microbial Community of Weaned Piglets}

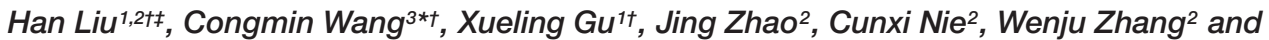 \\ Xi Ma' ${ }^{1,2 * \neq}$ \\ 'State Key Laboratory of Animal Nutrition, College of Animal Science and Technology, China Agricultural University, Beijing, \\ China, ${ }^{2}$ College of Animal Science and Technology, Shihezi University, Shihezi, China, ${ }^{3}$ Department of Dermatology, Seventh \\ Medical Center of Chinese PLA (People's Liberation Army) General Hospital, Beijing, China
}

The study investigated the impact of dietary montmorillonite on the growth performance, intestinal mucosal barrier, and microbial community in weaned piglets with control group $(\mathrm{CON})$ and dietary supplementation of $0.2 \%$ montmorillonite $(0.2 \% \mathrm{M})$. Compared with the CON group, $0.2 \% \mathrm{M}$ feed in the diet increased the average daily gain (ADG) on days 15-35 and day 1-35 and the average daily feed intake on days 1-35 (ADFI) $(0.05<P<0.1)$. Besides, higher villus height of the duodenum and jejunum and lower crypt depth of duodenum and colon were revealed in the $0.2 \% \mathrm{M}$ group than in the CON group $(P<0.05)$. Moreover, the $\mathrm{V} / \mathrm{C}$ (ratio of the villus height and crypt depth) in the $0.2 \% \mathrm{M}$ group was increased compared to that in the CON group both from the duodenum and ileum $(P<0.05)$. The relative mRNA expression of mucin-1, ITGB1 ( $\beta 1$ integrins), and PKC (protein kinase $C$ ) of ileum in the $0.2 \% \mathrm{M}$ group were upregulated $(P<0.05)$ compared to that in the CON group. The digesta sample of ileum from piglets in the $0.2 \% \mathrm{M}$ group contained greater $(P<0.05)$ intestinal bacterial diversity and abundances of probiotics, such as Streptococcus, Eubacterium_rectale_group, and Lactobacillus, which could promote the synthesis of carbon-containing biomolecules. Overall, dietary supplementation of $0.2 \% \mathrm{M}$ was shown to have a tendency to improve the growth performance of weaned piglets and may enhance their intestinal mucosal barrier function via altering the gut microbiota.

Keywords: montmorillonite, growth performance, intestinal mucosal barrier, intestinal bacteria community, weaned piglets

\footnotetext{
Abbreviations: NRC, National Research Committee; AOAC, Association of Official Analytical Chemists; BW, body weight: $\mathrm{ADG}$, average daily gain; ADFI, average daily feed intake; F:G, feed to gain ratio; V/C ratio of the villus height and crypt depth; MUCIN-1, mucin-1; ITGB1, $\beta 1$-integrins; PKC, protein kinase C; PCR, Polymerase Chain Reaction; OTUs, operational taxonomic units; $\mathrm{PCoA}$, principal co-ordinates analysis; LDA, linear discriminant analysis; LEfSe, linear discriminant analysis effect size; eggNOG, Evolutionary Genealogy of Genes: Non-supervised Orthologous Groups; KEGG: Kyoto Encyclopedia of Genes and Genomes; KW, Kruskal-Wallis; COG, Cluster of Orthologous Groups of proteins; PICRUSt, phylogenetic investigation of communities by reconstruction of unobserved states; SCFAs, short-chain fatty acids.
} 


\section{INTRODUCTION}

Ensuring that weaned piglets can grow healthily into the fattening stage is a key issue within pig breeding that has an effect on the economic benefit of the pig breeding industry. The intestinal nutrient metabolism during the weaning period undergoes a transition from liquid milk digestion to feed digestion (Wijtten et al., 2011). This process is prone to diseases, such as bacterial diarrhea (Heo et al., 2012; Huang et al., 2015) or viral gastroenteritis (Wang Q. et al., 2019), and even death, which may be caused by the impaired intestinal mucosal barrier function (Han et al., 2016; Ma et al., 2017). A healthy and efficient intestinal mucosal barrier and microbial community in weaned piglets can contribute to a safe and rapid transition for weaned piglets to the fattening stage (Heo et al., 2012). The active substances that could enhance the intestinal function and optimize intestinal microbes are therefore a powerful weapon with which to improve the gut health and growth performance of weaned piglets.

Montmorillonite, a layered silicate, possesses various physical and chemical properties, such as adsorption and swelling (Bhattacharyya and Gupta, 2008). It was also found to include anti-bacterial properties (Williams, 2008), enhancing immunity (Lee et al., 2015), and the intestinal mucosal barrier (Das et al., 2015). Recently, many studies (Song et al., 2012; Subramaniam and Kim, 2015) have reported that the montmorillonite has the potential to improve the intestinal barrier function, digestibility of nutrients, and growth performance of weaned piglets, which may be related to the changed gut microbiota (Xia et al., 2005; Wang et al., 2012). There has been, however, limited knowledge of the interactions between montmorillonite, the intestinal barrier, and intestinal bacteria community. In the present study, the growth performance, intestinal barrier function, and intestinal bacteria community of weaned piglets were investigated in terms of the efficacy of a supplement of $0.2 \%$ montmorillonite in order to provide a theory for rational and efficient utilization of montmorillonite as a feed supplement.

\section{MATERIALS AND METHODS}

All experimental operations and processing used in this work were approved by the Animal Care and Use Committee of China Agricultural University (Beijing, China). The montmorillonite used in this work ( $>95 \%$ purity) was obtained from Sanding Technology Company (Zhejiang, China).

\section{Animal Treatment and Experimental Design}

A total of 60 crossbred piglets (Duroc $\times$ Landrace $\times$ Large White) weaned at $28 \pm 1$ day of age, with an average initial body weight of $6.5 \pm 0.5 \mathrm{~kg}$, were randomly allocated to two dietary groups receiving a corn-soybean meal basal diet (CON group) or a corn-soybean meal basal diet supplemented with $0.2 \%$ montmorillonite $(0.2 \% \mathrm{M})$ according to weight, sex, and litter with six replicates (pens) of five piglets. Feed and water were available ad libitum throughout the 35 days feeding trial. The basal diet was formulated to meet the nutrient requirements recommended by the NRC. The ingredient composition and nutrient content of basal diet was given in Table 1. Diets were mixed for sample and grinded to pass through a $0.15 \mathrm{~mm}$ sieve. Dry matter, gross energy, crude protein, calcium and total phosphorus, ether extract, and ingredient contents of the basal diets were calculated according to the procedures of the Association of Official Analytical Chemists (AOAC) International. The body weight (BW) of piglets and feed were measured individually at the beginning, end of first 2 weeks, and end of the whole experiment to calculate the average daily gain (ADG), average daily feed intake (ADFI), and feed:gain (F:G) ratio.

\section{Sample Collection}

At the end of the experiment, six piglets closest to the average BW from each group (one pig per pen) were slaughtered after being fasted overnight $(12 \mathrm{~h})$, and the duodenum, jejunum, ileum, and colon were then sampled through a sterile laparotomy and placed in neutral formalin for histological analysis or collected in

TABLE 1 | The ingredient composition and nutrient content of diets (\%, as-fed basis) ${ }^{a}$.

\begin{tabular}{lccc}
\hline Items & Content (\%) & Nutrient levels & \\
\hline Ingredient & & GE (MJ/kg) & 16.95 \\
Extruded maize meal & 54.19 & DM (\%) & 91.41 \\
Dehulled soybean meal & 20.70 & CP (\%) & 20.26 \\
Extruded soybean & 11.00 & EE (\%) & 8.11 \\
Whey power & 4.00 & Ca (\%) & 0.87 \\
Fish meal & 3.00 & Total P (\%) & 0.71 \\
Wheat bran & 1.50 & & \\
Dicalcium phosphate & 2.20 & & \\
Glucose & 1.00 & & \\
Limestone & 0.80 & & \\
L-Lysine.HCl & 0.35 & & \\
L-Threonine & 0.18 & \\
DL-Methionine & 0.05 & & \\
Tryptophan & 0.03 & \\
Premix & 1.00 & \\
Total & 100 & \\
\hline a & & & \\
\hline
\end{tabular}

aData are the means of three replicates of analyzed values.

GE, Gross Energy; DM, Dry Matter; CP, Crude Protein; EE, Ether Extract; Ca, Calcium; P, Phosphorus.

Premix supplied per $\mathrm{kg}$ diet: vitamin A, 9,000 U; vitamin D3, 3,000 IU; vitamin E, $20 \mathrm{U}$; vitamin K3, $3 \mathrm{mg}$; vitamin B12, $0.2 \mathrm{mg}$; niacin, $30 \mathrm{mg}$; pantothenic acid, 15.0 mg; choline chloride, 400 mg; Zn, 75 mg; Mn, 60 mg; Fe, 75 mg; Cu, 150 mg; I, $0.35 \mathrm{mg}$; Se, $0.30 \mathrm{mg}$.

TABLE 2 | Primers used for quantitative RT-PCR.

\begin{tabular}{|c|c|c|}
\hline Gene & Forward $\left(5^{\prime}-3^{\prime}\right)$ & Reverse $\left(5^{\prime}-3^{\prime}\right)$ \\
\hline$\beta$-actin & ACACGGTGCCCATCTACGAG & GCTTCTCCTTGATGTCCCGC \\
\hline Occludin & CTITCTCAGCCAGCGTATTC & AGGCAAGCGTGGAGGCAACA \\
\hline Mucin-1 & CGGAAGCAGGCACCTATAAC & CAGAATACAGACCAGCACCA \\
\hline$\beta 1$-integrins & TAAGAGTGCCGTGACAACCG & TTCAGAACCTGCCCATAGCG \\
\hline Collagen & TGCTGCTGCTATTGTCCTTG & ACTGTGCCTTGGTGTTGGAT \\
\hline Protein kinase $\mathrm{C}$ & СТСАСТGCCACAACACAACT & GCACGAGCGGTTCTTCACTG \\
\hline
\end{tabular}


TABLE 3 | Effects of dietary supplement with $0.2 \%$ montmorillonite on growth performance in weaned piglets ${ }^{a}$.

\begin{tabular}{lccc}
\hline Item & CON & $\mathbf{0 . 2} \% \mathbf{~}$ & $\boldsymbol{P}$-value \\
\hline $\mathbf{1 - 1 4}$ days & & & \\
ADG & $227 \pm 28.3$ & $223.9 \pm 17.7$ & 0.25 \\
ADFI & $493.5 \pm 30.7$ & $474.6 \pm 32.6$ & 0.18 \\
F:G & $2.17 \pm 0.1$ & $2.12 \pm 0.3$ & 0.13 \\
$\mathbf{1 5 - 3 5}$ days & & & \\
ADG & $478 \pm 28.9$ & $1000.3 \pm 34.7$ & 0.09 \\
ADFI & $1057.9 \pm 30.5$ & $2.02 \pm 0.1$ & 0.11 \\
F:G & $2.22 \pm 0.1$ & & 0.15 \\
$\mathbf{1 - 3 5}$ days & & $386.8 \pm 20.9$ & \\
ADG & $377.5 \pm 16.9$ & $790.2 \pm 40.5$ & 0.07 \\
ADFl & $832.4 \pm 25.8$ & $2.04 \pm 0.3$ & 0.09 \\
F:G & $2.21 \pm 0.2$ & 0.13 \\
\hline
\end{tabular}

aData were shown as the mean \pm SEM $(n=30)$.

CON, basic diet control; $0.2 \% \mathrm{M}$, basic diet with $0.2 \%$ montmorillonite group; ADFI, average daily feed intake; $A D G$, average daily gain; F/G, ratio of $A D F I / A D G$.

centrifuge tubes and then immediately placed in liquid nitrogen and stored at the temperature of $-80^{\circ} \mathrm{C}$ for analysis of mRNA expression levels of $\beta$-actin, mucin-1 (MUCIN-1), $\beta 1$-integrins (ITGB1), collagen, occludin, and protein kinase $C(P K C)$ in ileal tissue. Briefly, about $1 \mathrm{~cm}$ length of the middle part of duodenum, jejunum, ileum, and colon were collected. The digesta of ileum and colon were obtained using centrifuge tubes and immediately placed in liquid nitrogen and then stored at the temperature of $-80^{\circ} \mathrm{C}$ for analysis of the bacterial community.

\section{Intestinal Morphology Analysis, RNA Extraction, and Quantitative RT-PCR Analysis}

Samples from duodenal, jejunal, ileal, and colonic segment were embedded in paraffin and cut into $5 \mu \mathrm{m}$ sections. Six non-successive sections of each sample were identified with hematoxylin and eosin staining. Six well-oriented villi and their associated crypt per section from each sample were collected. The villus height and crypt depth of duodenum, jejunum, ileum, and colon were measured and analyzed using a Leica Image Processing with Analysis System (Leica Imaging Systems Limited, Berlin, Germany). Total RNA extraction and quantitative realtime PCR analysis were conducted as described previously (Shen et al., 2014) with modifications. Briefly, TRIzol reagent (Invitrogen, Carlsbad, United States) was used to extract the total RNA of ileum after tissue homogenization and mixed with DNase I (Invitrogen, Carlsbad, United States). The obtained total RNA of IM (ileum with $0.2 \%$ montmorillonite) and INC (ileum negative control) were checked by $1 \%$ agarose gel electrophoresis and 2100 Bioanalyzer RNA Nanochip (Agilent, Palo Alto, United States). PrimeScript ${ }^{\mathrm{TM}}$ RT Reagent Kit (Takara, Dalian, China) was used to perform the reverse transcription of total RNA. Expression levels of $\beta$-actin, MUCIN-1, ITGB1, collagen, occludin, and $P K C$ in ileal tissue were analyzed by Roche LightCyler 480 system (Roche, Basel, Switzerland). The primer sequences for these six genes were showed in Table 2.
The RT-PCR system was: $10 \mu \mathrm{L}$ of $2 \times$ SYBR $^{\circledR}$ premix Ex TaqTM II, $0.6 \mu \mathrm{L}$ of each forward and reverse primer (10 $\mu \mathrm{mol} / \mathrm{L}), 2 \mu \mathrm{L}$ of complementary DNA template, and $6.8 \mu \mathrm{L}$ of double distilled water. The PCR reaction included an inactivation step at $95^{\circ} \mathrm{C}$ for $5 \mathrm{~min}$, and this was followed by 35 cycles of denaturation at $95^{\circ} \mathrm{C}$ for $10 \mathrm{~s}$, annealing at $60^{\circ} \mathrm{C}$ for $10 \mathrm{~s}$, and extension at $72^{\circ} \mathrm{C}$ for $15 \mathrm{~s}$. Each reaction was conducted to 20 $\mu \mathrm{L}$ using LightCycler 480 SYBR Green 1 Master (Roche, Basel, Switzerland). Each gene was performed with triplicate biological replicates and technical replicates. The result was calculated and represented by the $2^{-\Delta \Delta C T}$ method.

\section{Intestinal Microbial DNA Extraction and High-Throughput Sequencing}

Isolation of ileal and colonic content was performed using DNA Stool Mini Kit (Qiagen, Hilden, Germany). The quality and size of extracted DNA were checked via a NanoDrop 2000 spectrophotometer (Thermo Fisher Scientific, Waltham, United States) and 1\% agarose gel electrophoresis. The quantified DNA was stored in $-20^{\circ} \mathrm{C}$ for next analysis. Amplification of V3-V4 regions of the bacterial 16S rRNA gene was performed by TransStart FastpfuR DNA Polymerase (Takara, Dalian, China). The upstream primer and the downstream primer were $5^{\prime}$-barcode-ACTCCTACGGGAGGCAGCA-3' and $5^{\prime}$ GGACTACHVGGGTWTCTAAT-3', respectively. Amplification PCR reactions was conducted in $20 \mu \mathrm{L}$, with $10 \mathrm{ng}$ template DNA, 1U FastPfu polymerase, $1 \times$ FastPfu buffer, $250 \mu \mathrm{M}$ $\mathrm{dNTP}$, and $0.1 \mu \mathrm{M}$ each of the primer. PCR was under the reaction conditions of $95^{\circ} \mathrm{C}$ for $2 \mathrm{~min}, 95^{\circ} \mathrm{C}$ for $30 \mathrm{~s}, 55^{\circ} \mathrm{C}$ for $30 \mathrm{~s}, 72^{\circ} \mathrm{C}$ for $30 \mathrm{~s}$ for 30 cycles, and then $72^{\circ} \mathrm{C}$ for $5 \mathrm{~min}$. PCR products were firstly purified using AxyPrep DNA Purification kit (Axygen Biosciences, Union City, United States) after being run through $2 \%$ agarose gel electrophoresis. On agarose gels, the PCR products were quantified by QuantiFluor-ST Fluorimeter (Promega, Wisconsin, United States) using a PicoGreen dsDNA Quantitation Kit (Invitrogen, Carlsbad, United States). Purified amplicons were gathered in equimolar ratios for $2 \times 300 \mathrm{bp}$ sequencing by Illumina MiSeq in Shanghai Majorbio Bio-pharm Technology Co., Ltd. (Beijing, China) based on the standard protocols. Each treatment group was performed six replications.

\section{Bioinformatics Analysis of Sequencing Reads}

QIIME (version 1.9.1) and Fastp (version 0.19.6) were used for quality control and sequence filtering with the following criteria: (1) sequencing reads were clipped with an average quality score of $<20$; (2) reads shorter than 50 bp were dropped; (3) reads with two nucleotides of mismatch in primer sequences or ambiguous nucleotides were deleted; and (4) paired reads with less than $10 \mathrm{bp}$ overlap were discarded. Operational taxonomic units (OTUs) with a $97 \%$ identity cutoff were gathered by Uparse (version 7.0.1090) $)^{1}$, and the analysis of taxonomy of OTUs was performed using the Silva (Release132) 16 S rRNA database. The $\alpha$-diversity

\footnotetext{
${ }^{1}$ http://drive5.com/uparse/

${ }^{2}$ http://www.arb-silva.de
} 


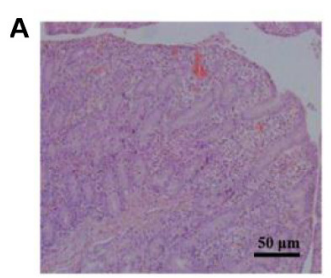

DNC

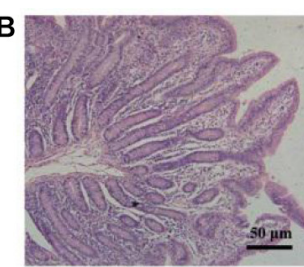

INC

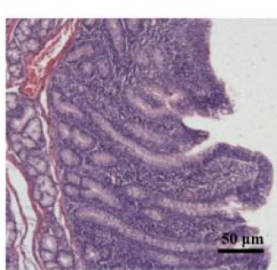

DM

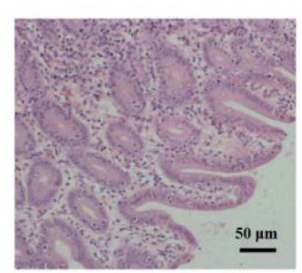

JNC

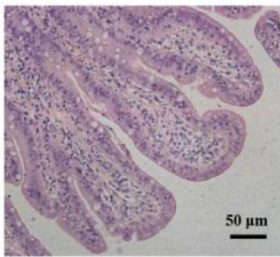

JM
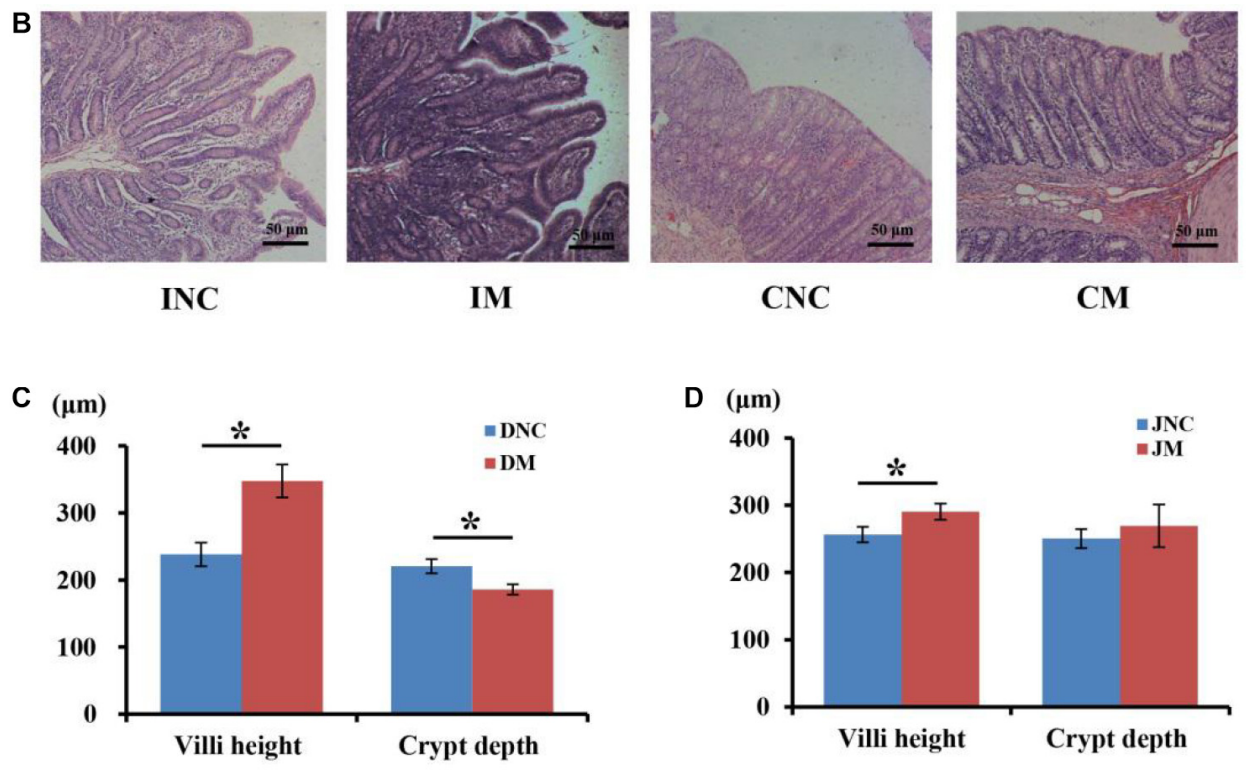

CNC

CM

D $(\mu \mathrm{m})$

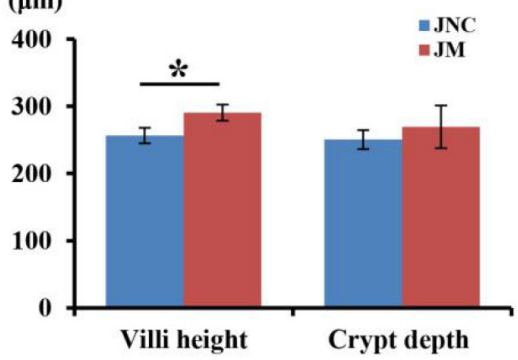

E $(\mu \mathrm{m})$

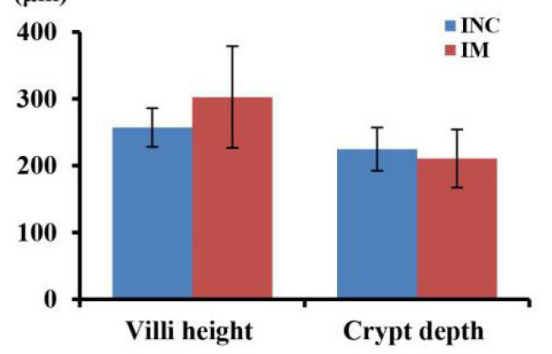

F $(\mu \mathrm{m})$

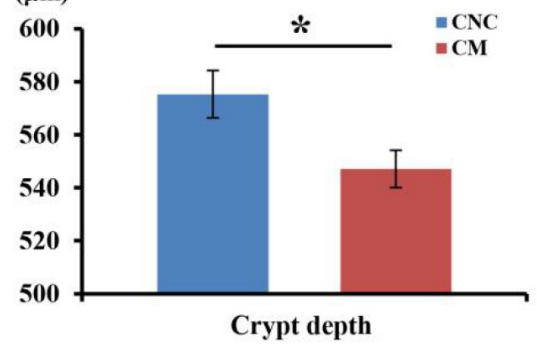

G

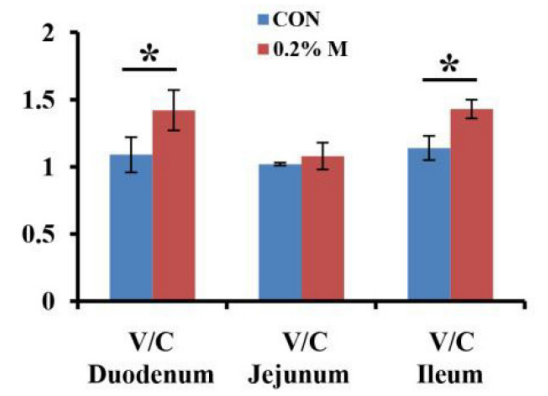

FIGURE 1 | Effects of 0.2\% montmorillonite on the small intestine and colon mucosal morphology. (A) Mucosal morphology of duodenum and jejunum from weaned piglets. (B) Mucosal morphology of ileum and colon from weaned piglets. The changes of villus height and crypt depth of (C) duodenum, (D) jejunum, and (E) ileum were investigated. (F) The changes of crypt depth of colon. (G) The ratio of the villus height and crypt depth (V/C) of duodenum, jejunum and ileum. Values are means \pm SEM, $n=6$. ${ }^{\star} P<0.05$. DNC, duodenum negative control; DM, duodenum with $0.2 \%$ montmorillonite; JNC, jejunum negative control; JM, jejunum with $0.2 \%$ montmorillonite; INC, ileum negative control; IM, lleum with $0.2 \%$ montmorillonite; CNC, colon negative control; CM, colon with $0.2 \%$ montmorillonite. 


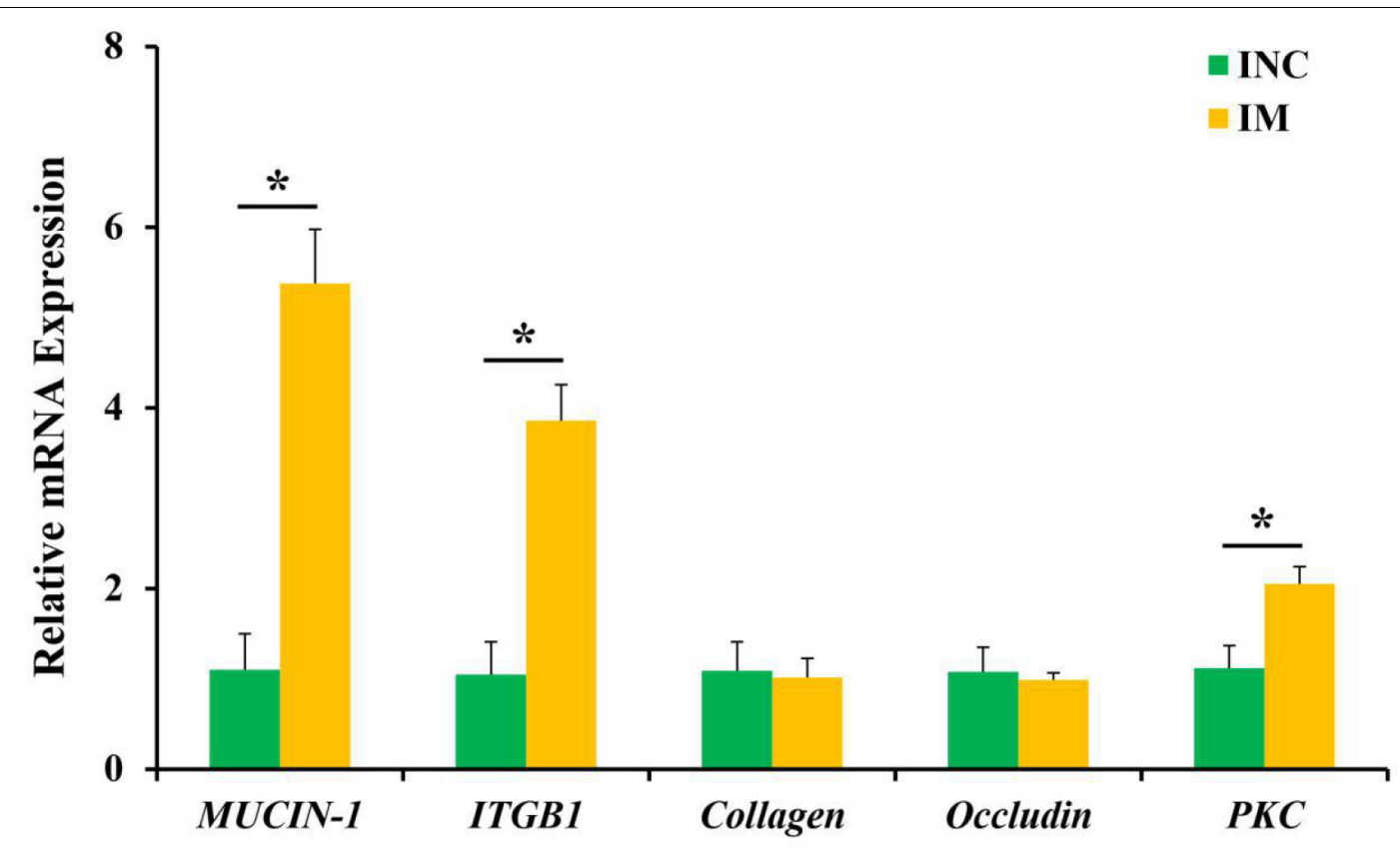

FIGURE 2 | Effects of $0.2 \%$ montmorillonite on the relative mRNA expressions of ileal barrier functional gene. Bate-actin was used as an internal standard for normalization. Values are means \pm SEM for three independent biological and technical replications, $n=6$. ${ }^{\star} P<0.05$. ITGB1, $\beta 1$-integrin; PKC, protein kinase C.

indices, including Chao 1 and Shannon, were analyzed by Mothur v.1.30.2. PCoA tools in R language were used for principal coordinates analysis (PCoA). The histogram of linear discriminant analysis (LDA) distribution was implemented using LDA effect size analysis (LEfSe) software. The 16S rRNA gene sequencing information was analyzed by PICRUSt to predict biological functions (EggNOG database) ${ }^{3}$ and metabolic pathways (KEGG database $)^{4}$ of the bacterial community of ileal and colonic contents samples of weaned piglets.

\section{Statistical Analysis}

The data (growth performance, intestinal morphology, and quantitative RT-PCR) analysis was performed by unpaired $t$-test of SPSS 19.0. Results are represented as means \pm SEM. The data ( $\alpha$-diversity indices, predictive analysis of metabolic functions, and metabolic pathways) analysis was performed via a Wilcoxon rank-sum test. LDA analysis was performed by non-parametric factorial Kruskal-Wallis (KW) sum-rank test. $P$-value $<0.05$ was considered as statistically significant.

\section{RESULTS}

\section{Growth Performance}

The results shown that there are no significantly difference in the ADG, ADFI and F:G $(P>0.05)$ of weaned piglets no matter what period during the whole experiment (Table 3). However, the $0.2 \%$

${ }^{3}$ http://eggnog.embl.de/

${ }^{4}$ http://www.genome.jp/kegg/
M has shown a tendency to improve the ADG during days 15-35 and $1-35$ as well as the ADFI during days $1-35(0.05<P<0.1)$.

\section{Intestinal Mucosal Morphology}

The mucosal morphology of the duodenum, jejunum, ileum, and colon were obtained in Figure 1. The villus height of DM (duodenum with $0.2 \%$ montmorillonite) and JM (jejunum with $0.2 \%$ montmorillonite) was significantly higher $(P<0.05)$ than that in DNC (duodenum negative control) and JNC (jejunum negative control), respectively (Figures 1C,D). Conversely, the crypt depth in DM and CM (colon with $0.2 \%$ montmorillonite) was significantly lower $(P<0.05)$ than that in DNC and CNC (colon negative control), respectively (Figures 1C,F). The differences of the villus height and crypt depth (Figure 1E) between IM and INC were non-significant, respectively $(P>0.05)$. Besides, the $\mathrm{V} / \mathrm{C}$ (ratio of the villus height and crypt depth) in the $0.2 \% \mathrm{M}$ group was significantly increased $(P<0.05)$ in comparison to that in the CON group for both the duodenum and ileum (Figure 1G).

\section{Intestinal Barrier Function}

The relative mRNA expression of ileal barrier function-related genes is displayed in Figure 2. A diet containing 0.2\% $\mathrm{M}$ has been shown to upregulate $(P<0.05)$ the relative mRNA expression of $M U C I N-1, I T G B 1$, and $P K C$ in the ileum of piglets (Figure 2). However, the relative mRNA expressions of collagen and occludin have shown no significantly difference $(P>0.05)$ between the $\mathrm{CON}$ and $0.2 \% \mathrm{M}$ groups in the ileum of piglets (Figure 2). 
TABLE 4 | Statistics of bacterial 16S rRNA gene amplicon sequencing for ileal and colonic content ${ }^{a}$.

\begin{tabular}{|c|c|c|c|}
\hline Group ID & Clean reads & Average length (bp) & OTUs \\
\hline INC1 & 48,572 & 424.62 & 186 \\
\hline INC2 & 61,439 & 413.79 & 250 \\
\hline INC3 & 25,883 & 416.95 & 233 \\
\hline INC4 & 47,961 & 415.08 & 248 \\
\hline INC5 & 34,086 & 417.09 & 217 \\
\hline INC6 & 34,817 & 414.54 & 251 \\
\hline CNC1 & 36,927 & 420.27 & 399 \\
\hline $\mathrm{CNC2}$ & 21,440 & 417.53 & 508 \\
\hline CNC3 & 45,335 & 415.20 & 466 \\
\hline CNC4 & 34,634 & 417.17 & 483 \\
\hline CNC5 & 54,390 & 416.75 & 465 \\
\hline CNC6 & 24,961 & 425.23 & 266 \\
\hline IM1 & 35,696 & 435.53 & 297 \\
\hline IM2 & 30,865 & 433.52 & 314 \\
\hline IM3 & 34,132 & 435.96 & 303 \\
\hline IM4 & 34,666 & 433.90 & 346 \\
\hline IM5 & 31,539 & 433.92 & 333 \\
\hline IM6 & 33,761 & 433.66 & 307 \\
\hline CM1 & 33,011 & 431.03 & 455 \\
\hline $\mathrm{CM} 2$ & 44,915 & 432.13 & 457 \\
\hline CM3 & 32,829 & 430.11 & 447 \\
\hline CM4 & 36,228 & 431.58 & 400 \\
\hline CM5 & 39,203 & 431.15 & 459 \\
\hline CM6 & 37,810 & 434.97 & 411 \\
\hline
\end{tabular}

aINC, Ileum negative control; CNC, Colon negative control; IM, lleum with $0.2 \%$ montmorillonite; CM, Colon with $0.2 \%$ montmorillonite.

Sequences with similarity scores $\geq 0.97$ were clustered into an OTU.

\section{The Bacterial Community of Digesta From the lleum and Colon}

To investigate the effects of montmorillonite on the bacterial community structure of weaned piglets, we performed 16S rRNA gene sequencing of content samples from the ileum and colon. After sequence quality control, a total of 470445 as well as 424655 clean reads (Table 4 ) were obtained from the CON and $0.2 \% \mathrm{M}$ group, respectively. The OTUs numbers of INC, CNC, IM, and CM with six biological replications are also listed in Table 4. Based on OTUs information, bioinformatics analysis was further performed. The coverage curves (Figures 3A,B) showed flat trend with the increasing of sequencing reads, indicating that the sequencing reads in this experiment were sufficient to reveal the bacterial diversity of content samples from ileum and colon. Besides, the Shannon index in IM was higher $(P<0.05)$ than that in INC (Figure 3D), while there were no significantly difference in the Chao 1 index of the ileum and colon and the Shannon index of the colon between the $\mathrm{CON}$ and $0.2 \% \mathrm{M}$ groups (Figures 3C,D). PCoA analysis (Figures 3E,F) showed a clear differentiation $\left(P_{I M-I N C}<0.05\right.$, $\left.P_{C M-C N C}<0.05\right)$ between the CON and $0.2 \% \mathrm{M}$ groups both in the microbiota present in ileum and colon, indicating that the addition of montmorillonite changed the bacterial community structure in ileum and colon.
At the phylum level, the relative abundance of Firmicutes in IM and INC was slightly changed (95.7 vs. $95.6 \%$ ), and the relative abundance of Firmicutes in CM (77.6 vs. 88.5\%) was enhanced compared to CNC. The relative abundance of Actinobacteria in IM (0.1 vs. $1.6 \%)$ and CM (0.8 vs. $1.6 \%)$ was enhanced (Figure 4A), while the Proteobacteria in IM (4.0 vs. $0.4 \%)$ and the Bacteroidetes in CM (20.3 vs. $8.3 \%)$ was reduced compared to that in INC an CNC (Figure 4B), respectively. At the genera level, the relative abundance of the top 20 bacterial communities in INC, IM, CNC, and CM is listed in the heatmap (Figures 4C,D). The relative abundance of Clostridium_sensu_stricto_1, Bacillus, Paenibacillus, and Terrisporobacter, the dominant genera in INC, was decreased in IM (36.7 vs. $15.7 \%$; 27.3 vs. $<0.01 \%$; 10.1 vs. $<0.01 \%$; 5.1 vs. $3.7 \%$ ), and the dominant genera in IM changed to Streptococcus (24.2\%), Clostridium_sensu_stricto_1 (15.7\%), [Eubacterium_rectale_group (13.8\%), and Lactobacillus (13.2\%), which was richer than that in INC (Figure 4C). In the colon, the dominant genera including Streptococcus (35.3\%), Lactobacillus (12.1\%), norank_f_Bacteroidales_S24-7_group (10.4\%), and [Eubacterium]_coprostanoligenes_group (5.5\%) in CNC changed to Clostridium_sensu_stricto_1 (39.5\%), Streptococcus (10.3\%), and Lactobacillus (7.1\%) in CM (Figure 4D). In addition, the relative abundance of Clostridium_sensu_stricto_1, Terrisporobacter, Subdoligranulum, and Blautia dramatically increased, but the Streptococcus, Rikenellaceae_RC9_gut_group and Christensenellaceae_R-7_group reduced in CM in comparison to CNC (Figure 4D).

All differential bacteria of the ileum and colon were demonstrated from the phylum to species level in cladogram of LEfSe between CON and $0.2 \% \mathrm{M}$ groups (Figures 5A,B). At the phylum level, the relative abundance of Proteobacteria in the ileum and the Bacteroidetes in the colon were significantly lower $(P<0.05)$ in $0.2 \% \mathrm{M}$ group than that in CON group (Figures 5A,B). In the genera level, the relative abundance of Bacillus, Paenibacillus, Enterococcus, Alkaliphilus, Cronobacter, and Lactococcus were markedly abated $(P<0.05)$, while the relative abundance of Streptococcus, Eubacterium_rectale_group, Lactobacillus, Faetobacterium, Subdoligranulum, Blautia, Eubacterium_coprostanoligenes_group, and Ruminococcaceae_UCG_014 were signally boosted $(P<0.05)$ in IM instead of INC (Figure 5C). Moreover, the relative abundance of Streptococcus were dramatically reduced $(P<0.05)$, but the relative abundance of Clostridium_sensu_stricto_1, Subdoligranulum, Terrisporobacter, and Blautia were observably enhanced $(P<0.05)$ in CM instead of CNC (Figure 5D).

\section{Predicted Functional Profiles of Microbial Communities Using PICRUSt}

To predict the potential function of gut bacteria on nutrient metabolism in piglets after feeding on a diet with and without the montmorillonite, biological functions and KEGG pathways were analyzed by the PICRUSt program. Seventeen notably different predicted biological functions (COG level 1) and 20 markedly different KEGG pathways between INC and IM and 14 different predicted biological functions and 14 different KEGG pathways between CNC and CM were detected in Figures 6, 

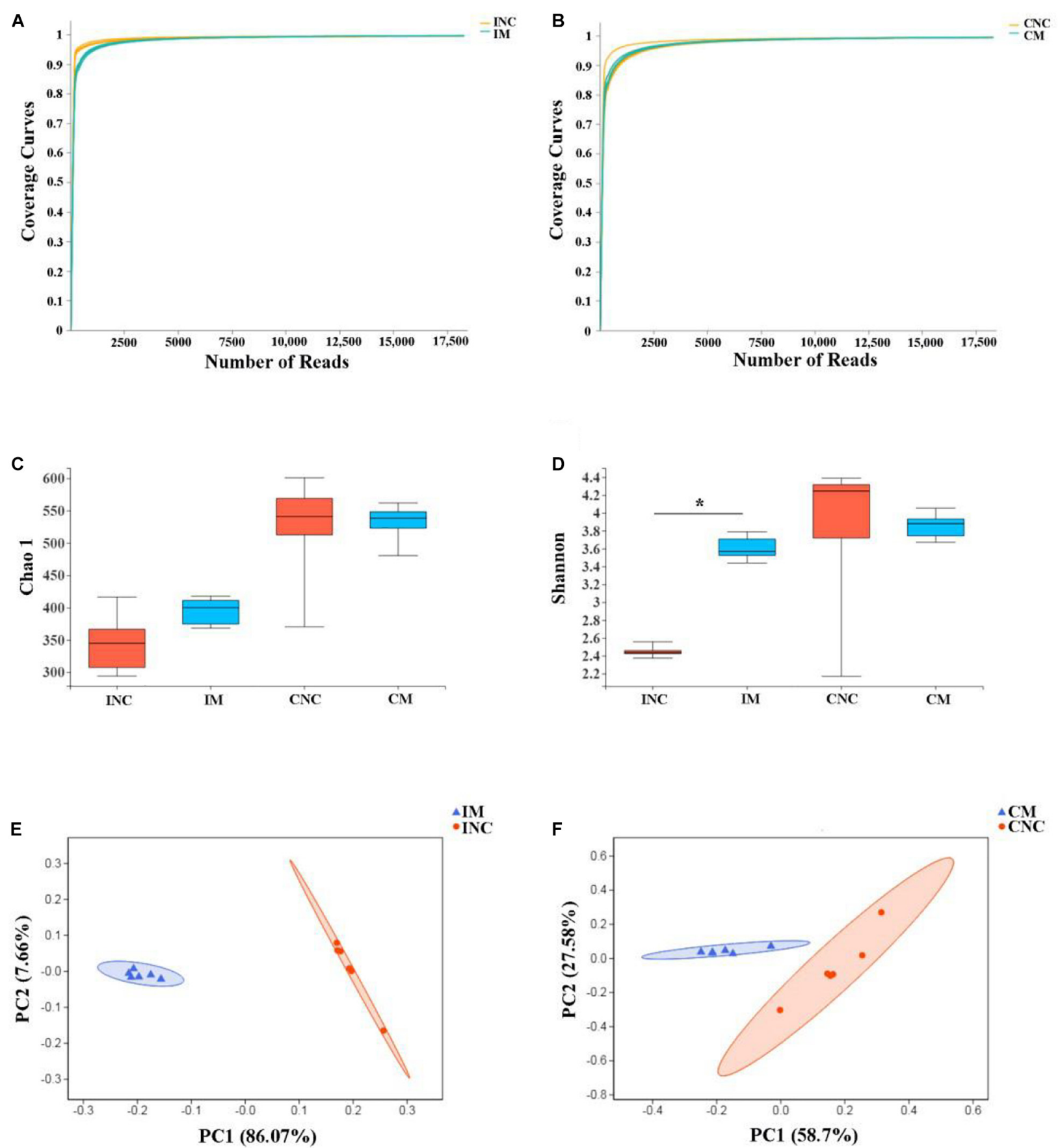

FIGURE 3 | Alpha diversity and PCOA of bacterial communities between control and montmorillonite treatments in ileum and colon from weaned piglets. Sequencing coverage curves of negative control (INC) and (A) basal diet with $0.2 \%$ montmorillonite (IS) from the ileum and negative control (CNC) and (B) basal diet with $0.2 \%$ montmorillonite (CS) from the colon. (C) Chao 1 index of bacterial community and (D) Shannon index of bacterial community in four groups. The PCoA analyses of bacterial communities between control and montmorillonite treatment group from (E) ileum and $\mathbf{F}$ ) colon. The results were analyzed by Wilcoxon rank-sum test and ${ }^{*} P<0.05$.

7. Beyond this, bacteria with carbohydrate transport and metabolism, translation, ribosomal structure and biogenesis, cell wall/membrane/envelope biogenesis, defense mechanisms, and nucleotide transport and metabolism functions were significantly more enriched $(P<0.01)$ in IM than in INC (Figure 6A).
The predicted metabolic pathways involved in microorganisms, such as carbohydrate metabolism, replication and repair, translation, energy metabolism, and nucleotide metabolism, were significantly enriched $(P<0.01)$ in IM compared to INC (Figure 7A). In the colon, significantly increased bacteria after 

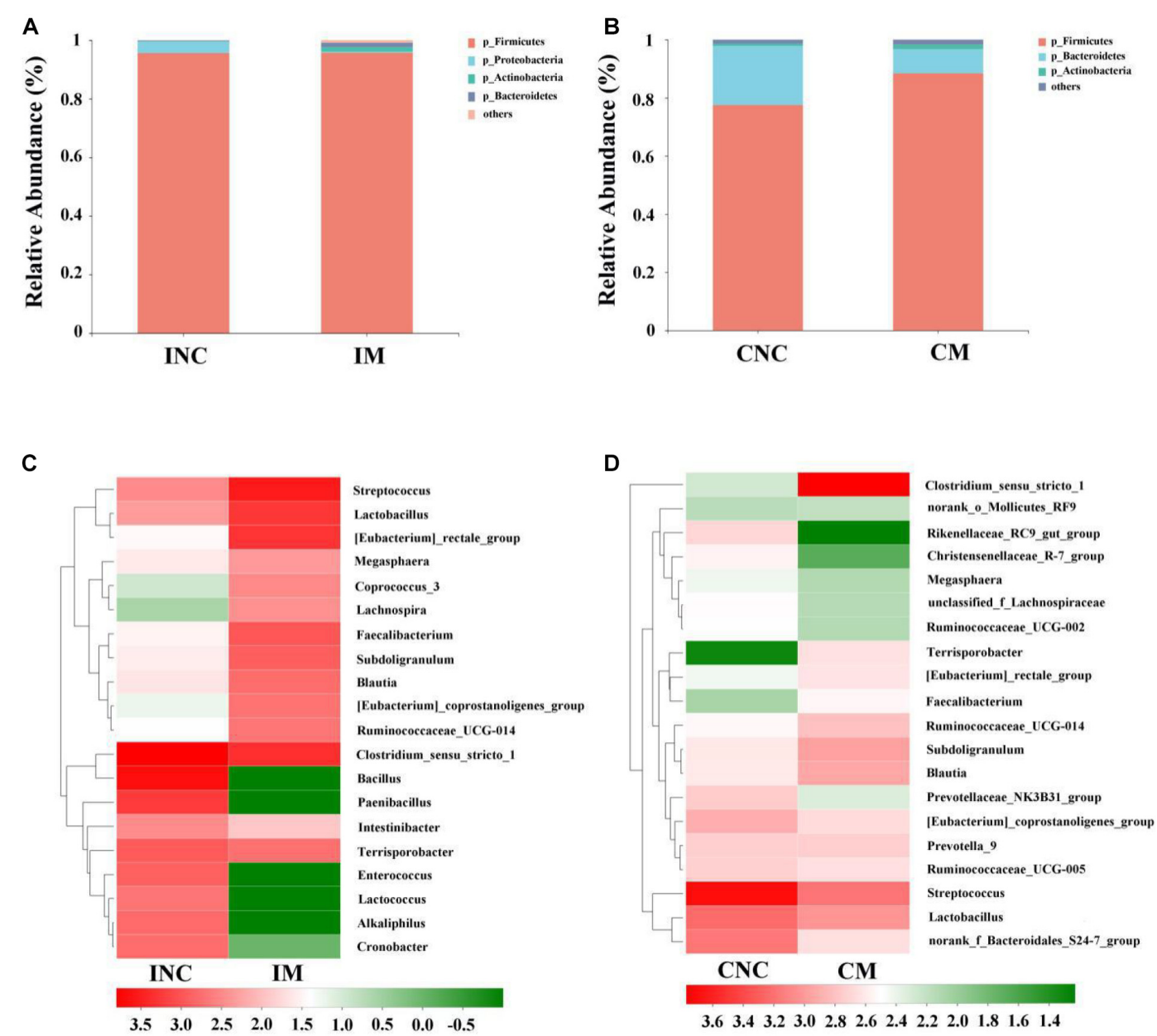

FIGURE 4 | Bacterial diversity at the phylum and genus level in the ileum and colon from weaned piglets of control and treatment group. (A) Bacterial community barplot of INC and IM at the phylum level in ileum. (B) Bacterial community barplot of CNC and CM at the phylum level in colon. (C) Bacterial community barplot of INC and IM at the genus level in ileum. (D) Bacterial community barplot of CNC and CM at the genus level in colon. INC, ileum negative control; CNC, colon negative control; IM, ileum with $0.2 \%$ montmorillonite; $\mathrm{CM}$, colon with $0.2 \%$ montmorillonite.

dietary supplementation of $0.2 \%$ montmorillonite improved $(P<0.01)$ the functions of transcription, amino acid transport and metabolism, replication, recombination and repair, and signal transduction mechanisms (Figure 6B). The number of significantly changed predicted metabolic pathways between $\mathrm{CNC}$ and $\mathrm{CM}$ were reduced. In CM (Figure 7B), amino acid metabolism, cellular processes and signaling, and transcription were significantly enriched $(P<0.01)$.

\section{DISCUSSION}

Montmorillonite is widely used as a feed additive, and its characteristics of improving the growth performance of animals have attracted much attention (Yu et al., 2008; Duan et al., 2013; Yang et al., 2014; Jiao et al., 2015, 2018). Yu et al. (2008) reported that the addition of $0.5 \%$ montmorillonite had significantly improved the weight gain, feed intake, and feed conversion ratio of pigs. However, in the present study, the
ADG, ADFI, and F:G of weaned piglets were not significantly changed after the addition of $0.2 \%$ montmorillonite except for an improvement trend in ADG and ADFI during days 15-35 and $1-35$, respectively. Similarly with our study, the addition of graded concentration of montmorillonite only changed the feed intake without improving the weight gain of pigs (Duan et al., 2013). It is also reported that adding montmorillonite to the feed did not improve the growth performance of pigs (Xia et al., 2005; Song et al., 2012). Interestingly, relying on the adsorption of montmorillonite, feeding montmorillonite loaded with copper and zinc ions, which are beneficial to growth, showed a significant improvement in the growth performance of pigs (Jiao et al., 2015, 2018); this is an indication that the single addition of montmorillonite has a limited effect on improving the growth performance of weaned piglets.

Although the superior growth performance of weaned piglets was not achieved after adding the montmorillonite to the diet, it has the potential to improve the intestinal barrier function (Song et al., 2012; Subramaniam and Kim, 2015). Intestinal 


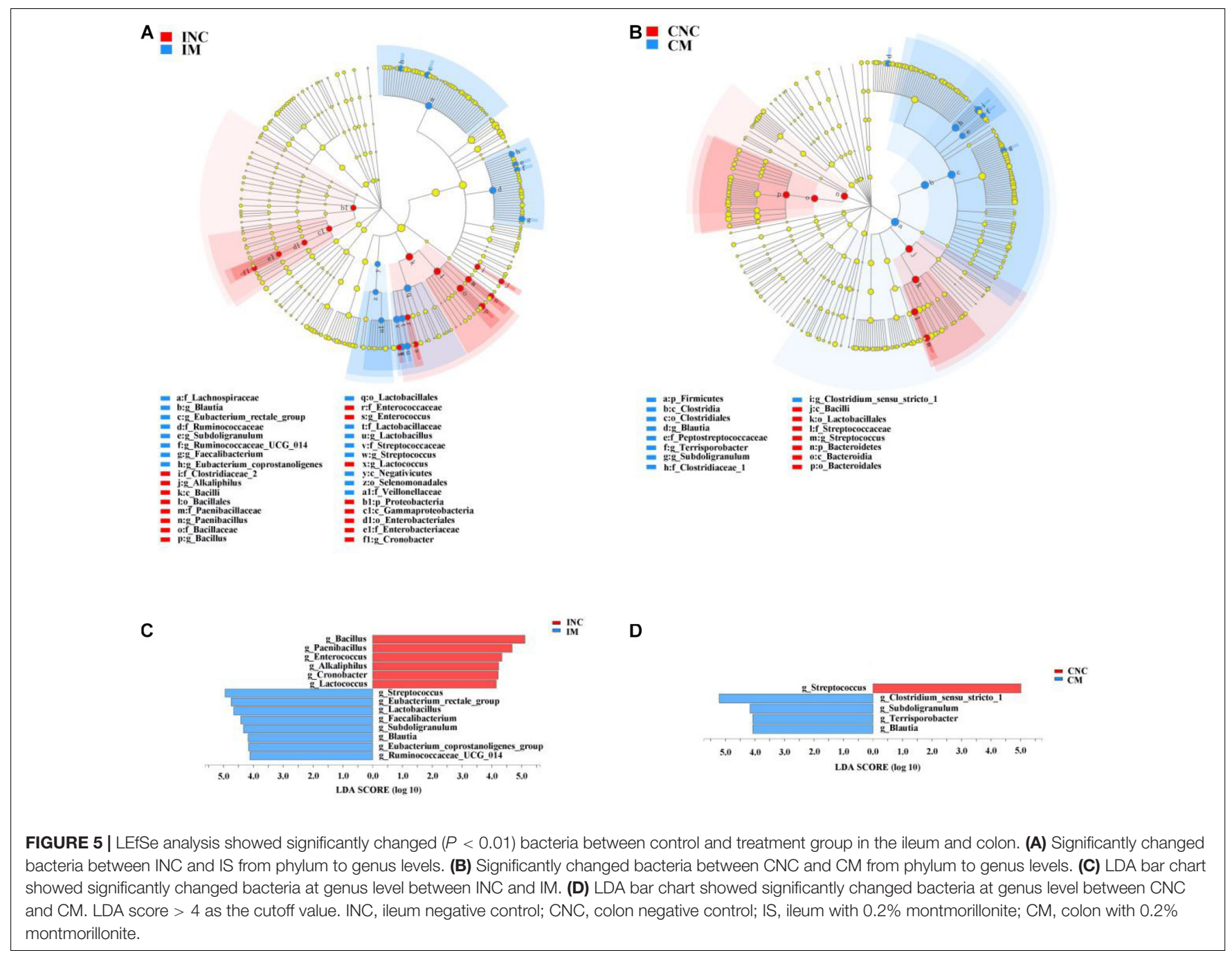

mucosal barriers include physical barriers, chemical barriers, immune barriers, and microbial barriers, while intestinal mucosal morphology involves the function of intestinal physical barrier. The short villi not only causes an increase in the intestinal epithelial permeability, increasing the inflammatory response and amplifying the dysfunction of the intestinal motor function, but also leads to a decrease in the intestinal absorption area, which may affect the normal intake of piglets (Collins, 2001; Liu et al., 2017). Besides, the crypt is involved in the generation and transportation of epithelial cells, and the decrease of crypt depth can increase the rate of mature cells (Clevers, 2013; Liu et al., 2014). In the present study, we found that the weaned piglets fed with the $0.2 \%$ montmorillonite diet exhibited a higher villus height in the duodenum and jejunum compared with the CON group. Meanwhile, lower crypt depth of the duodenum and colon were revealed in the $0.2 \% \mathrm{M}$ group than in the CON group, and the $\mathrm{V} / \mathrm{C}$ in the $0.2 \% \mathrm{M}$ group was significantly increased in comparison to that in the CON group for both the duodenum and ileum. These results hinted that the montmorillonite could improve the surface area for nutrient absorption, thus increasing nutrient digestibility (Clevers, 2013; Liu et al., 2014) as well as increase the intestinal defense function by improving the intestinal mucosal morphology, which may be relate to the altering of the gut microbiota (Xia et al., 2004; Shameli et al., 2011; Placha et al., 2014).

To further confirm the effect of montmorillonite on intestinal barrier function, the relative mRNA expression of intestinal mucosal barrier-related gene (MUCIN-1, ITGB1, collagen, occluding, and $P K C$ ) from the ileum were measured by qRTPCR. The results shown that the relative mRNA expression of ileal MUCIN-1, ITGB1, and PKC were upregulated in the $0.2 \% \mathrm{M}$ group vs. the CON group, while the relative mRNA expression of ileac collagen and occludin have no significantly difference between the two groups. Mucins are mainly involved in maintaining the structure and function of intestinal mucosa and regulating the intestinal microorganisms (Mcguckin et al., 2011). Integrins, including ITGB1, are the major receptors for extracellular matrix, and regulate the assembly of adhesive junctions in the intestinal tract, and then play roles in the rapid renewal and digestive functions of intestinal tract (Breau et al., 2009). PKC is another important protein that is expressed by gastrointestinal cells and regulates intracellular signaling 


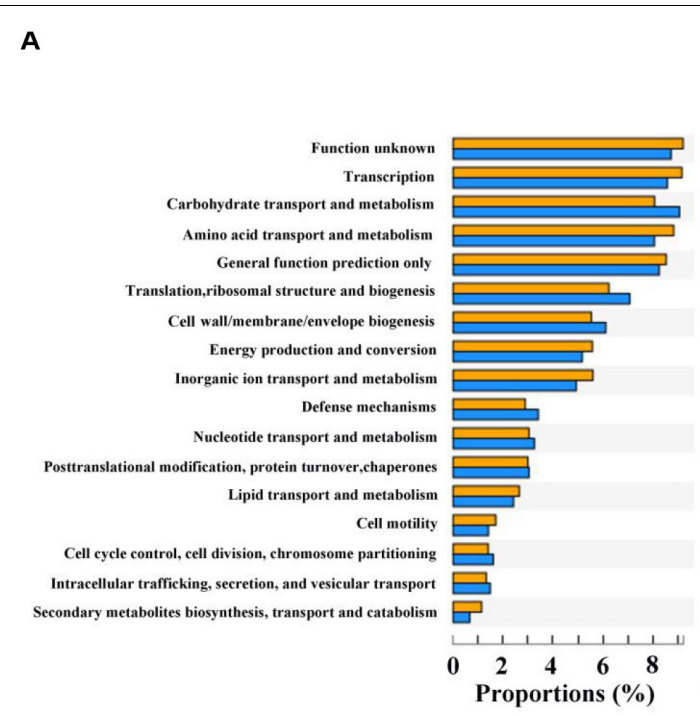

B

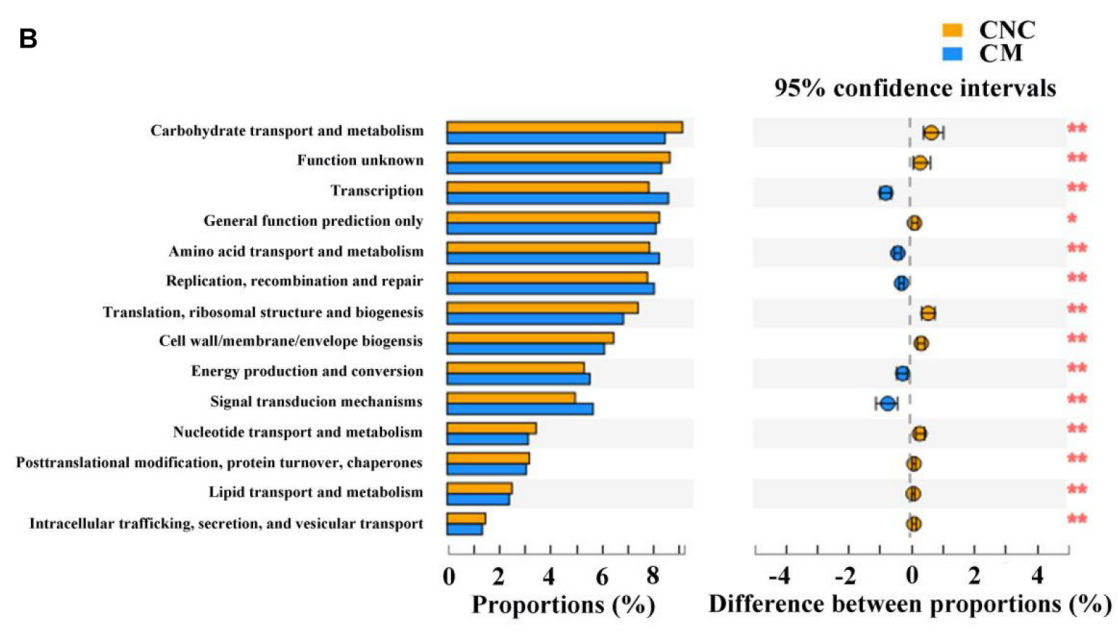

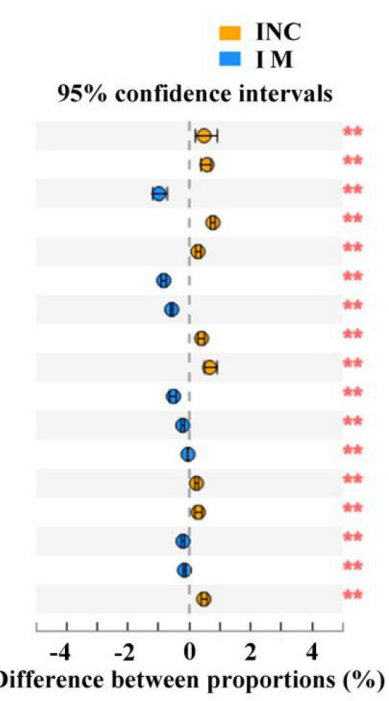

Difference between proportions (\%)

FIGURE 6 | Comparison of the bacterial predicted biological functions (COG level 1) between control and treatment group from the ileum and colon using PICRUSt. (A) COG function prediction analysis of ileal bacteria between INC and IM. (B) COG function prediction analysis of colonic bacteria between CNC and CM. INC, ileum negative control; CNC, colon negative control; IM, ileum with $0.2 \%$ montmorillonite; CM, colon with $0.2 \%$ montmorillonite. ${ }^{\star} P<0.05$ and ${ }^{\star *} P<0.01$.

and barrier integrity (Farhadi, 2005). That the relative mRNA expression of ileal MUCIN-1, ITGB1, and PKC were upregulated by adding montmorillonite revealed that the addition of montmorillonite improved the intestinal barrier function $\mathrm{Hu}$ et al., 2012; Jiao et al., 2015, 2018; Chen J. F. et al., 2019, 2020); this was caused by the swelling property of montmorillonite, which will cause the volume of intake feed to become larger, slowing down the time of passing through the intestinal tract and promoting the metabolism of intestinal epidermal cells (Subramaniam and Kim, 2015).

Gut microbiota, serving as microbial barriers in intestinal mucosal barriers, play an important role in intestinal function; these functions involve nutrient absorption, mucosal barrier homeostasis, immunomodulation, and defense against pathogens for pigs (Huang et al., 2015; Fan et al., 2017). It is reported that the montmorillonite improved the intestinal barrier function, digestibility of nutrients, and growth performance of weaned piglets by regulating the gut microbiota (Xia et al., 2005; Wang et al., 2012). In the present study, the Shannon index, one of the $\alpha$-diversity indices, of ileum was more increased in the $0.2 \% \mathrm{M}$ group compared with the $\mathrm{CON}$ group, which indicated that the addition of $0.2 \%$ montmorillonite to the feed promoted the growth of ileal bacteria in weaned piglets and improved the diversity of the microbial community. The bacterial diversity is an indicator of a healthy and stable gut microbial community, which is beneficial to the host (Salonen et al., 2012). Besides, the results of PCoA analyses proved that there is a significant difference in the microbial community composition between the $\mathrm{CON}$ and $0.2 \% \mathrm{M}$ groups, which was demonstrated in that the structure and composition of gut microbiota on weaned piglets will be changed by the montmorillonite. 
A

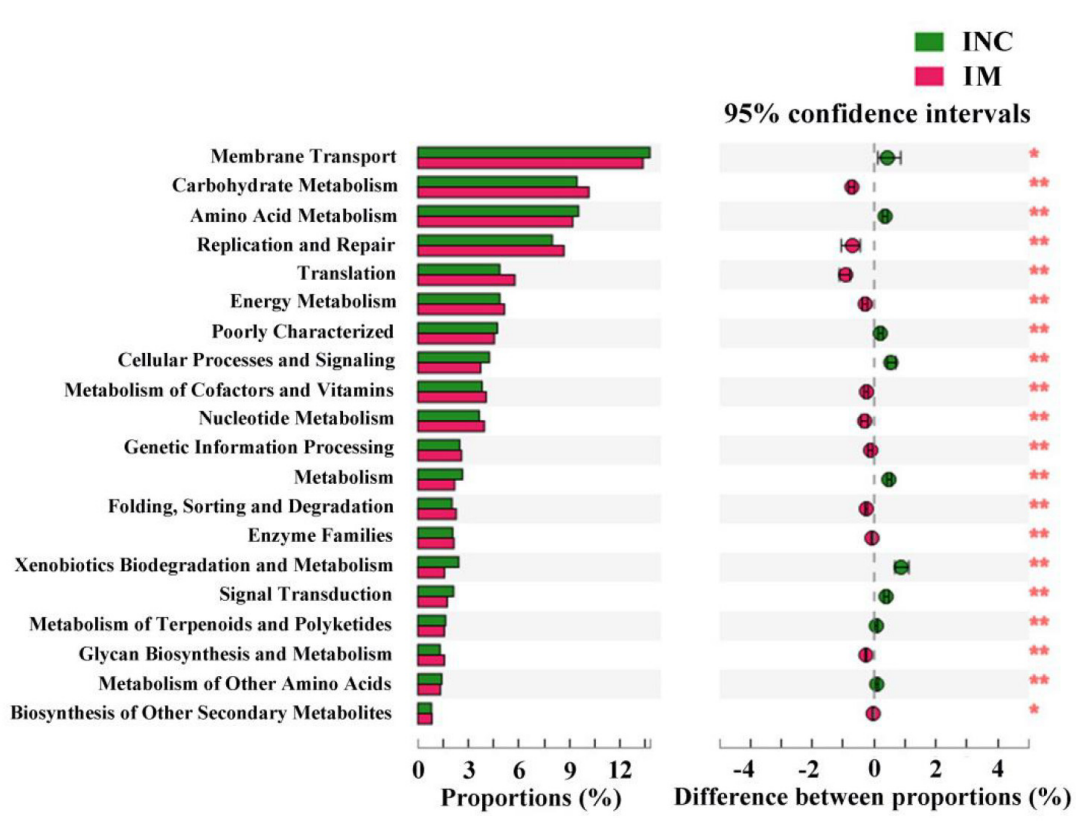

B

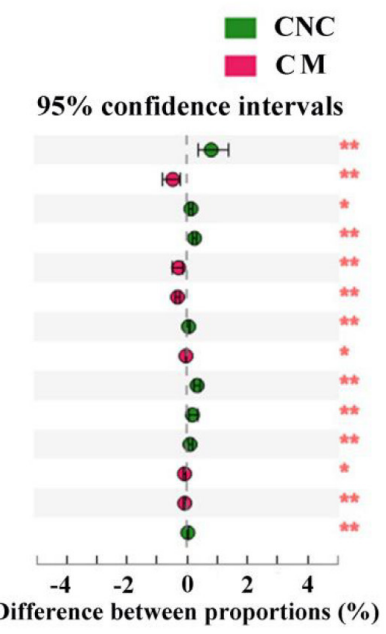

FIGURE 7 | The mean proportion and significant difference in predicted metabolism pathways (KEGG) between control and treatment group from the ileum and colon using PICRUSt. (A) KEGG pathways analysis of ileal bacteria between INC and IM. (B) KEGG pathways analysis of colonic bacteria between CNC and CM. INC, ileum negative control; CNC, colon negative control; IM, ileum with $0.2 \%$ montmorillonite; $\mathrm{CM}$, colon with $0.2 \%$ montmorillonite. ${ }^{\star} P<0.05$ and ${ }^{\star *} P<0.01$.

At the phylum level, the $0.2 \% \mathrm{M}$ group saw a decreased relative abundance of Proteobacteria in iluem compared to the CON group in the present study. The Proteobacteria are a minor constituent within a balanced gut-associated microbial community (Eckburg et al., 2005). Recent studies have proposed that an expansion of the Proteobacteria could be a potential diagnostic microbial signature of epithelial dysfunction as well as dysbiosis in the gut microbiota (Na-Ri et al., 2015). Besides, the relative abundance of Bacteroidetes was decreased, but the Firmicutes was increased in the colon after supplementing the montmorillonite into the diets of weaned piglets. The Firmicutes and Bacteroidetes are the dominate phylum in the gut microbiota of piglets, and the increase in Firmicutes was considered a means of enhancing the body's capacity for energy acquisition from the diet, which may improve the growth of piglets (Turnbaugh et al., 2006).

In the genera level, the relative abundance of Streptococcus, Eubacterium_rectale_group, and Lactobacillus in the ileum was increased by adding the montmorillonite to the diets. Streptococcus is considered to be involved in the process of intestinal nutrition metabolism, such as amino acid utilization (Neis et al., 2015) and the production of short-chain fatty acids (Corr et al., 2009); and butyrate belonged to shortchain fatty acids (SCFAs) contributes to maintaining intestinal 
homeostasis (Iacob and Iacob, 2019). In addition, the D-alanine (Miyauchi et al., 2012) and exopolysaccharide (Chen Y. et al., 2019), produced by Streptococcus thermophilus, and the yogurt fermented by Streptococcus thermophilus 1131 (Usui et al., 2018) can improve the intestinal barrier mucosal function and alleviate intestinal inflammation. Moreover, the Eubacterium rectale participated in the butyrogenic effect of dietary fermentation (Louis et al., 2007). The growth of Eubacterium rectale was inhibited in a gut model from ulcerative colitis patients, indicting Eubacterium rectale might promote intestinal function through butyrate metabolism (Joan et al., 2012). Lactobacillus is considered to be a probiotic with the function of enhancing human and animal health (Colum et al., 2001). In addition, Lactobacillus is believed to be involved in the production of butyrate (Berni Canani et al., 2016). As an immunoregulatory factor, butyrate maintains the intestinal barrier and immune homeostasis; meanwhile, it also promotes the release of antimicrobial peptides and de-represses microbial virulence factors against pathogen invasion (Iacob and Iacob, 2019). The increase in Lactobacillus might therefore further improve the intestinal metabolism and growth performance of weaned piglets in the manner of butyrate metabolism. In the colon, meanwhile, the microflora was changed slightly. For instance, the relative abundance of Clostridium_sensu_stricto_1 and Subdoligranulum, which can produce SCFAs, was more enhanced in the $0.2 \% \mathrm{M}$ group compared with the CON group, which may be due to that the montmorillonite mainly contribute to the foregut rather than hindgut (Wang L. et al., 2019). Furthermore, using the PICRUSt program to predict functional profiles of microbial communities of the ileum and colon, we found the number of gene tags involved in the synthesis of carbon-containing biomolecules in lieum and the number of gene tags involved in the energy production and conversion and the amino acid metabolism in colon were markedly more enhanced in the $0.2 \% \mathrm{M}$ group compared with the CON group. The result suggests that $\mathrm{Xu}$ et al., 2017; Lee et al., 2018) the montmorillonite supplementation may be involved in carbohydrate metabolism and amino acid metabolism by altering the gut microbiota that can product the SCFAs, but it is necessary to conduct further study into the relationship between montmorillonite supplementation and carbohydrate and amino acid metabolism.

\section{CONCLUSION}

Overall, dietary supplementation of $0.2 \%$ montmorillonite has displayed a slight influence on the growth performance of weaned

\section{REFERENCES}

Berni Canani, R., Sangwan, N., Stefka, A. T., Nocerino, R., Paparo, L., Aitoro, R., et al. (2016). Lactobacillus rhamnosus GG-supplemented formula expands butyrate-producing bacterial strains in food allergic infants. Isme J. 10, 742-750. doi: 10.1038/ismej.2015.151

Bhattacharyya, K. G., and Gupta, S. S. (2008). Adsorption of a few heavy metals on natural and modified kaolinite and montmorillonite: A review. Adv. Colloid. Interface. Sci. 140, 114-131. doi: 10.1016/j.cis.2007.12.008 piglets. However, $0.2 \%$ montmorillonite supplementation improved the intestinal mucosal morphology and increased the relative mRNA expression of intestinal mucosal barrier functionrelated genes by altering gut microbiota. These findings will contribute to a better understanding of how montmorillonite modulates gut health through nutrient intervention.

\section{DATA AVAILABILITY STATEMENT}

The original contributions presented in the study are publicly available. This data can be found here: https://www.ncbi.nlm.nih. gov/PRJNA667820.

\section{ETHICS STATEMENT}

The animal study was reviewed and approved by the Animal Care and Use Committee of China Agricultural University.

\section{AUTHOR CONTRIBUTIONS}

$\mathrm{XM}$ conceived and designed the research. HL, CW, and XG conducted the research. HL wrote the manuscript and analyzed the data. JZ and XG wrote a part of manuscript and assisted in analysis of data. XG and XM critically reviewed the manuscript. XG contributed to language review. All authors read and approved the final manuscript.

\section{FUNDING}

This work was supported by the National Key R\&D Program of China (2018YFD0500601 and 2017YFD0500501), the National Natural Science Foundation of China (31930106, 31829004, and 31722054), the National Ten-thousand Talents Program of China (23070201), and the 111 Project (B16044).

\section{ACKNOWLEDGMENTS}

Our profound admiration and respect go to researchers in this field and in our laboratories for their dedication and hard work. We apologize to scientists whose work is in this field if their manuscripts are not cited owing to space limitations.

Breau, M. A., Dahmani, A., Broders-Bondon, F., Thiery, J., and Dufour, S. (2009). $B 1$ integrins are required for the invasion of the caecum and proximal hindgut by enteric neural crest cells. Development 136, 2791-2801. doi: 10.1242/dev. 031419

Chen, J. F., Liu, X., Qu, X., and Guo, S. (2019). Montmorillonite improved the intestinal mucosal barrier functions of laying hens in late production. J. Anim. Physiol. An. N. 103, 1081-1089. doi: 10.1111/jpn.13094

Chen, J. F., Xu, M. M., Kang, K. L., Tang, S. G., He, C. Q., Qu, X. Y., et al. (2020). The effects and combinational effects of Bacillus subtilis and montmorillonite 
on the intestinal health status in laying hens. Poultry Sci. 99, 1311-1319. doi: 10.1016/j.psj.2019.11.016

Chen, Y., Zhang, M., and Ren, F. A. (2019). Role of Exopolysaccharide Produced by Streptococcus thermophilus in the Intestinal Inflammation and Mucosal Barrier in Caco-2 Monolayer and Dextran Sulphate SodiumInduced Experimental Murine Colitis. Molecules 24:513. doi: 10.3390/ molecules 24030513

Clevers, H. (2013). The intestinal crypt, a prototype stem cell compartment. Cell 154, 274-284. doi: 10.1016/j.cell.2013.07.004

Collins, S. M. (2001). Stress and the Gastrointestinal Tract IV. Modulation of intestinal inflammation by stress: basic mechanisms and clinical relevance. Am. J. Physiol. Gastrointest. Liver Physiol. 280, G315-G318. doi: 10.1152/ajpgi.2001. 280.3.G315

Colum, D., Liam, O., Lisa, M., Gerardine, T., Darrin, M., Sile, O., et al. (2001). In vitro selection criteria for probiotic bacteria of human origin: correlation with in vivo findings. Am. J. Clin. Nutr. 73, 386S-392S. doi: 10.1093/ajcn/73.2. $386 \mathrm{~s}$

Corr, S. C., Hill, C., and Gahan, C. G. (2009). Understanding the mechanisms by which probiotics inhibit gastrointestinal pathogens. Adv. Food Nutr. Res. 56, 1-15. doi: 10.1016/S1043-4526(08)00601-603

Das, R. R., Sankar, J., and Naik, S. S. (2015). Efficacy and safety of diosmectite in acute childhood diarrhoea: a meta-analysis. Arch. Dis. Child 100, 704-712.

Duan, Q. W., Li, J. T., Gong, L. M., Wu, H., and Zhang, L. Y. (2013). Effects of graded levels of montmorillonite on performance, hematological parameters and bone mineralization in weaned pigs. Asian Australas J. Anim. Sci. 26, 1614-1621. doi: 10.5713/ajas.2012.12698

Eckburg, P. B., Bik, E. M., Bernstein, C. N., Purdom, E., Dethlefsen, L., Sargent, M., et al. (2005). Diversity of the human intestinal microbial flora. Science 308, 1635-1638. doi: 10.1126/science.1110591

Fan, P., Liu, P., Song, P., Chen, X., and Ma, X. (2017). Moderate dietary protein restriction alters the composition of gut microbiota and improves ileal barrier function in adult pig model. Sci. Rep. UK. 7:43412. doi: 10.1038/srep43412

Farhadi, A. (2005). The Role of Protein Kinase C Isoforms in Modulating Injury and Repair of the Intestinal Barrier. J. Pharmacol. Exp. Ther. 316, 1-7. doi: 10.1124/jpet.105.085449

Han, M., Song, P., Huang, C., Rezaei, A., Farrar, S., Brown, M. A., et al. (2016). Dietary grape seed proanthocyanidins (GSPs) improve weaned intestinal microbiota and mucosal barrier using a piglet model. Oncotarget 7, 3031330326. doi: 10.18632 /oncotarget. 13450

Heo, J. M., Opapeju, F. O., Pluske, J. R., Kim, J. C., and Nyachoti, C. M. (2012). Gastrointestinal health and function in weaned pigs: A review of feeding strategies to control post-weaning diarrhoea without using in-feed antimicrobial compounds. J. Anim. Physiol. An. N. 97, 207-237. doi: 10.1111/j. 1439-0396.2012.01284.x

Hu, C., Song, J., You, Z., Luan, Z. S., and Li, W. (2012). Zinc OxideMontmorillonite Hybrid Influences Diarrhea, Intestinal Mucosal Integrity, and Digestive Enzyme Activity in Weaned Pigs. Biol. Trace Elem. Res. 149, 190-196.

Huang, C., Song, P., Fan, P., Hou, C., Thacker, P., and Ma, X. (2015). Dietary Sodium Butyrate Decreases Postweaning Diarrhea by Modulating Intestinal Permeability and Changing the Bacterial Communities in Weaned Piglets. J. Nutr. 145, 2774-2780. doi: 10.3945/jn.115.217406

Iacob, S., and Iacob, D. G. (2019). Infectious Threats, the Intestinal Barrier, and Its Trojan Horse: Dysbiosis. Front. Microbiol. 10:1676. doi: 10.3389/fmicb.2019. 01676

Jiao, L. F., Ke, Y. L., Xiao, K., Song, Z. H., Lu, J. J., and Hu, C. H. (2015). Effects of zinc-exchanged montmorillonite with different zinc loading capacities on growth performance, intestinal microbiota, morphology and permeability in weaned piglets. Appl. Clay Sci. 11, 40-43. doi: 10.1016/j.clay.2015. 04.012

Jiao, L. F., Zhang, Q. H., Wu, H., Wang, C. C., Cao, S. T., Feng, J., et al. (2018). Influences of Copper/Zinc-Loaded Montmorillonite on Growth Performance, Mineral Retention, Intestinal Morphology, Mucosa Antioxidant Capacity, and Cytokine Contents in Weaned Piglets. Biol. Trace Elem. Res. 185, 356-363.

Joan, V., Pieter, V. D. A., Debby, L., Kristine, V. L., Martine, D. V., Nico, B., et al. (2012). Decreased colonization of fecal Clostridium coccoides/Eubacterium rectale species from ulcerative colitis patients in an in vitro dynamic gut model with mucin environment. Fems. Microbiol. Ecol. 79, 685-696. doi: 10.1111/j. 1574-6941.2011.01252.x
Lee, E. S., Song, E. J., Lee, S. Y., Park, S. L., Kim, D., Kim, D., et al. (2018). Effects of Bentonite Bgp35b-p on the Gut Microbiota of Mice Fed a High-Fat Diet. J. Sci. Food Agr. 98, 4369-4373. doi: 10.1002/jsfa.8934

Lee, J., Bock-Gie, J., Tae-Hoon, K., Yun-Mi, K., Hong-Bum, K., and BongJoo, L. (2015). Improvement of bacterial clearance and relief of clinical signs of Salmonella enterica serovar Typhimurium infection in pigs through upregulation of Th 1-specific responses by administration of a combination of two silicate minerals, biotite and bentonite. J. Vet. Med. Sci. 77, 1087-1094. doi: $10.1292 /$ jvms.14-0362

Liu, M., Zhang, B., Yu, C., Li, J., Zhang, L., Sun, H., et al. (2014). L-Glutamate Supplementation Improves Small Intestinal Architecture and Enhances the Expressions of Jejunal Mucosa Amino Acid Receptors and Transporters in Weaning Piglets. PLoS One. 9:e111950. doi: 10.1371/journal.pone.0111950

Liu, M., Zhu, D., Guo, T., Zhang, Y., Shi, B., Shan, A., et al. (2017). Toxicity of zearalenone on the intestines of pregnant sows and their offspring and alleviation with modified halloysite nanotubes. J. Sci. Food Agric. 98, 698-706. doi: $10.1002 /$ jsfa. 8517

Louis, P., Scott, K. P., Duncan, S. H., and Flint, H. J. (2007). Understanding the effects of diet on bacterial metabolism in the large intestine. J. Appl. Microbiol. 102, 1197-1208. doi: 10.1111/j.1365-2672.2007.03322.x

Ma, N., Wu, Y., Xie, F., Du, K. X., Wang, Y., Shi, L. X., et al. (2017). Dimethyl fumarate reduces the risk of mycotoxins via improving intestinal barrier and microbiota. Oncotarget 8, 44625-44638. doi: 10.18632/oncotarget.17886

Mcguckin, M. A., Lindén, S. K., Sutton, P., and Florin, T. H. (2011). Mucin dynamics and enteric pathogens. Nat. Rev. Microbiol. 9, 265-278. doi: 10.1038/ nrmicro2538

Miyauchi, E., Morita, M., Rossi, M., Morita, H., Suzuki, T., and Tanabe, S. (2012). Effect of D-Alanine in Teichoic Acid from the Streptococcus thermophilus Cell Wall on the Barrier-Protection of Intestinal Epithelial Cells. Biosci. Biotechnol. Biochem. 76, 283-288. doi: 10.1271/bbb.110646

Na-Ri, S., Tae Woong, W., and Jin-Woo, B. (2015). Proteobacteria: microbial signature of dysbiosis in gut microbiota. Trends Biotechnol. 33, 496-503. doi: 10.1016/j.tibtech.2015.06.011

Neis, E. P., Dejong, C. H., and Rensen, S. S. (2015). The role of microbial amino acid metabolism in host metabolism. Nutrients 7, 2930-2946. doi: 10.3390/ nu7042930

Placha, D., Rosenbergova, K., Slabotinsky, J., Kutlakova, K. M., Studentova, S., and Martynkova, G. S. (2014). Modified clay minerals efficiency against chemical and biological warfare agents for civil human protection. J. Hazard. Mater. 271, 65-72. doi: 10.1016/j.jhazmat.2014.01.059

Salonen, A., Salojarvi, J., Lahti, L., and de Vos, W. M. (2012). The adult intestinal core microbiota is determined by analysis depth and health status. Clin. Microbiol. Infect. 18(Suppl. 4), 16-20. doi: 10.1111/j.1469-0691.2012.03855.x

Shameli, K., Madya, M. B. A., Yunis, W. Z., Ibrahim, N. A., Mohsen, Z., Shabanzadeh, P., et al. (2011). Synthesis and characterization of silver/montmorillonite/chitosan bionanocomposites by chemical reduction method and their antibacterial activity. Int. J. Nanomed. 6, 271-284. doi: 10. 2147/IJN.S16043

Shen, J., Chen, Y., Wang, Z., Zhou, A., He, M., Mao, L., et al. (2014). Coated zinc oxide improves intestinal immunity function and regulates microbiota composition in weaned piglets. Br. J. Nutr. 111, 2123-2134. doi: 10.1017/ S0007114514000300

Song, M., Liu, Y., Soares, J. A., Chen, T. M., Osuna, O., Maddox, C. W., et al. (2012). Dietary clays alleviate diarrhea of weaned pigs. J. Anim. Sci. 90, 345-360. doi: $10.2527 /$ jas.2010-3662

Subramaniam, M. D., and Kim, I. H. (2015). Clays as dietary supplements for swine: A review. J. Anim. Sci. Biotechnol. 6:38.

Turnbaugh, P. J., Ley, R. E., Mahowald, M. A., Vincent, M., Mardis, E. R., and Gordon, J. I. (2006). An obesity-associated gut microbiome with increased capacity for energy harvest. Nature 444, 1027-1031. doi: 10.1038/nature05414

Usui, Y., Kimura, Y., Satoh, T., Takemura, N., Ouchi, Y., Ohmiya, H., et al. (2018). Effects of long-term intake of a yogurt fermented with Lactobacillus delbrueckii subsp. bulgaricus 2038 and Streptococcus thermophilus 1131 on mice. Int. Immunol. 30, 319-331. doi: 10.1093/intimm/dxy035

Wang, J. P., Chi, F., and Kim, I. H. (2012). Effects of montmorillonite clay on growth performance, nutrient digestibility, vulva size, faecal microflora, and oxidative stress in weaning gilts challenged with zearalenone. Anim. Feed. Sci. Technol. 178, 158-166. doi: 10.1016/j.anifeedsci.2012.09.004 
Wang, L., Gong, L., Zhu, L., Peng, C., Liao, J. L., Ke, L. F., et al. (2019). Effects of activated charcoal-herb extractum complex on the growth performance, immunological indices, intestinal morphology and microflora in weaning piglets. Rsc Adv. 9, 5948-5957. doi: 10.1039/c8ra10283j

Wang, Q., Vlasova, A. N., Kenney, S. P., and Saif, L. J. (2019). Emerging and reemerging coronaviruses in pigs. Curr. Opin. Virol. 34, 39-49. doi: 10.1016/j. coviro.2018.12.001

Wijtten, P. J. A., Meulen, J. V. D., and Verstegen, M. W. A. (2011). Intestinal barrier function and absorption in pigs after weaning: a review. Brit. J. Nutr. 105, 967-981. doi: 10.1017/S0007114510005660

Williams, S. E. H. C. (2008). Broad-spectrum in vitro antibacterial activities of clay minerals against antibiotic-susceptible and antibiotic-resistant bacterial pathogens. J. Antimicrob. Chemoth. 61, 353-361. doi: 10.1093/jac/ dkm468

Xia, M. S., Hu, C. H., and Xu, Z. R. (2005). Effects of copper bearing montmorillonite on the growth performance, intestinal microflora and morphology of weanling pigs. Anim. Feed. Sci. Technol. 118, 307-317. doi: 10.1016/j.anifeedsci.2004.11.008

Xia, M. S., Hu, C. H., Xu, Z. R., Ye, Y., Zhou, Y. H., and Xiong, L. (2004). Effects of Copper-bearing Montmorillonite (Cu-MMT) on Escherichia coli and Diarrhea on Weanling Pigs. Asian Austral. J. Anim. 17, 1712-1716. doi: 10.5713/ajas. 2004.1712
Xu, P., Hong, F., Wang, J., Cong, Y., Dai, S., Wang, S., et al. (2017). Microbiome Remodeling via the Montmorillonite Adsorption-Excretion Axis Prevents Obesity-related Metabolic Disorders. EBio Med. 16, 251-261. doi: 10.1016/j. ebiom.2017.01.019

Yang, L., Zhao, Z., Deng, Y., Zhou, Z., and Hou, J. (2014). Toxicity induced by F. Poae-contaminated feed and the protective effect of montmorillonite supplementation in broilers. Food. Chem. Toxicol. 74, 120-130. doi: 10.1016/j. fct.2014.09.011

Yu, D. Y., Li, X. L., and Li, W. F. (2008). Effect of Montmorillonite Superfine Composite on Growth Performance and Tissue Lead Level in Pigs. Biol. Trace Elem. Res. 125, 229-235.

Conflict of Interest: The authors declare that the research was conducted in the absence of any commercial or financial relationships that could be construed as a potential conflict of interest.

Copyright (c) 2020 Liu, Wang, Gu, Zhao, Nie, Zhang and Ma. This is an open-access article distributed under the terms of the Creative Commons Attribution License (CC BY). The use, distribution or reproduction in other forums is permitted, provided the original author(s) and the copyright owner(s) are credited and that the original publication in this journal is cited, in accordance with accepted academic practice. No use, distribution or reproduction is permitted which does not comply with these terms. 